\section{Editorial: Drowning in Data?}

\author{
IAN LIVINGSTONE
}

I a recent Telecom In Touch newsletter, an article entitled Technology delivers the future... today, notes that over half of all New Zealanders now have access to the Internet, either at work or at home, and that we send an average of 900,000 Emails every day. ${ }^{1}$ We are amongst the top users of the Internet per head of population in the world, and Internet traffic now accounts for 60 percent of all local traffic on our telephone lines.

A correspondent in the June 2001 issue of New Zealand PC World confessed (if confessed is indeed the right word) to writing about 22,000 Emails during the past year, and receiving more than twice that number. ${ }^{2}$ This works out at approximately 120 incoming Emails to be dealt with, and 60 new ones written and sent off, every day of the year! The writer also noted that, of these incoming Emails, about 3,500 had attachments, of which he read only about 60 percent. This is just one indicator of a stupendous amount of data pouring over the airwaves, much of it unread. But is this really what communication is all about?

We need to ask ourselves how much of this data being transmitted is in fact information. How much of it is actually read or even scanned? Of that, how much is actually digested? Of that, how much is actually regarded as informative or useful or wanted? Furthermore, how much of this Internet surfing is actually safe? There is now virtually no censorship possible of what goes onto the Internet, and although various efforts have been made to shield young people from undesirable material, and more importantly perhaps, from undesirable personal contacts through Email "chat rooms", "Net Nannies" are at best only minimally effective screens. The technology explosion has outpaced our morality.

There is also the question of validating information passed over the Internet. Editors of traditional "paper" journals with reputations to uphold pass articles submitted for publication through professionallyapproved processes of peer review (as does this journal). There is some
2 Ian Livingstone

assurance that peers knowledgeable in the field have scrutinised each contribution, and come to some agreement with the author and editor that it passes normal canons of accurate and well-documented research. Most reputable Internet journals do the same. But the potential for a vast amount of un-validated and inaccurate information to be downloaded is enormous. It is simply a case of "surfer-beware".

For several years, members of the Editorial Board of the New Zealand Annual Review of Education have pondered over the future of the large and distinctive Reference Section contained in the back of the publication, with its carefully-compiled, underpinning diary of news from the education sector, lists of education-related legislation, and its select, but quite extensive, keyworded bibliography of research articles and theses on educational topics. Over the years, it has proved expensive and very time-consuming to prepare, but it has generally been regarded as valuable, particularly for students.

Now that virtually every enquirer has easy Internet access to on-line resources which can provide this information, we have made the decision in this issue to completely revise the Reference Section. The improved and streamlined Te Puna databases provided by the New Zealand National Library, plus all the computerised resources in tertiary institution libraries, mean that the data are all there, just waiting to be turned into useful information, provided efficient search strategies are employed. We aim to provide just such strategies in this issue in our Reference Section, so that enquirers can find what they want, tailored precisely to their requirements.

The first article in the current issue has made extensive use of such referencing, and traces the history of assessment in the secondary school, particularly in relation to the philosophy of standards-based assessment espoused by the recently announced National Certificate of Educational Achievement. It then explores the problems that are likely to arise when the School Certificate and University Bursary examinations are abolished and the NCEA positioned as the only remaining qualification for senior secondary school students, and argues that in the final analysis, the success (or otherwise) of the NCEA will ultimately be determined by the acceptance of this qualification in the community.

The next article also has a strong information focus, and summarises the process used in developing the Ministry of Education's "Strategic Research Initiative", and the thinking behind it, in particular the literature reviews published by the Ministry in 2000. Each of the reviews 
is briefly described to indicate some of the key themes which might guide Ministry staff to identify potential priorities for strategic research in education-related topics.

Next follow two papers with a Pacific Islands focus. The first (which is also this year's Early Childhood contribution) is by three authors, led by Dr Val Podmore, and provides an overview of some current difficulties for Pacific nations children in their transition to school from early childhood services in New Zealand. It highlights some key issues arising from a study, reported during the year under review, on transition to school from Pacific Islands early childhood services.

John Dickie was the winner of the Rae Munro award at the Annual Conference of the New Zealand Association for Research in Education (December, 2000). From his winning MEd thesis, investigating how Wellington College of Education staff could support Pacific nations students to complete primary teacher training successfully, he is able to draw out some specific and more general implications for Pacific nations students entering teacher training in New Zealand.

Then follow our two curriculum pieces. Kama Weir deals with sexuality education, a complex and highly contested area of the curriculum in New Zealand schools. This article retraces the values education debate of the 1970s and 1980s and draws parallels with contemporary issues in values education, particularly sexuality education.

Christina Thornley and two teaching colleagues examine English in the New Zealand Curriculum, mandated some years ago as curriculum policy for New Zealand classrooms. Their paper describes a research case study undertaken in two Year One classrooms where the children's work in exploring language is analysed against the prescribed achievement levels. It raises concerns about the possible underestimation of children's abilities in literacy learning.

Then come three papers dealing with various aspects of teacher education. A key element of the National Education Monitoring Project in New Zealand has been the employment of specially trained, practising teachers to work intensively with groups of children over a five week period in at least five different schools. This study by Alison Gilmore documents the nature and level of professional development gained by these teachers through this experience, and finds it to be very highly valued and very extensive.

Teacher accountability has been the focus of a series of Government reports and enactments over the past 15 years. An article by Debby
Upsall argues that since the publication of Tomorrow's Schools, Government policy making has been dominated by a managerialist approach at odds with the priorities of many educationalists. Changing the focus to foster internal accountability would encourage teachers to be reflective professionals seeking to improve their own practices. But with adequate resourcing, it should be possible to ensure the dual purposes of professional development and management appraisal can both be attained.

There are now some 750 Resource Teachers: Learning and Behaviour (RTLB) in New Zealand, following implementation of the Special Education 2000 policy. A mandatory requirement for those taking up these positions is that they undertake a professional development programme consisting of four graduate or postgraduate papers. In the next article, Elizabeth Jones outlines the rationale for including a professional practice portfolio as the final paper in this programme, and discusses some early findings about its implementation, from both RTLB and faculty perspectives.

Our final article is by Keith Sullivan, who describes the results of a case study of a particular low-decile school, whose principal and teachers contested vigorously against officialdom to create a culture of success within the context of current educational reforms, very much against the odds. They eventually were able to put in place a range of innovative initiatives within their difficult teaching environment. As a means of generating more understanding, the article finishes by exploring first of all the role of "teacher as hero" as portrayed in film, and secondly the relationship between schooling and cultural capital.

This is a significant year for the School of Education at Victoria University and its flagship publication, the New Zealand Annual Review of Education. With this issue it completes its tenth year of production. I believe the vision of its founders has been amply confirmed by the fact that its circulation has substantially increased since the mid-90s, and remains high for an educational publication of its type in a small, but literate, country. The journal has proved a vehicle for a large volume of constructively critical research and review in the educational scene over the decade. It is my pleasure to have been associated with the review as editor over the last six of those years, and I hereby salute all who have contributed in any way, large or small, to its undoubted success.

Notes

1. Enoka, D. (2001, June). Technology delivers the future ... today. In Touch.

2. Bass, S. (2001, June). Email: Manage the medium. New Zealand PC World, 20 